\title{
Source rupture processes of the 1944 Tonankai earthquake and the 1945 Mikawa earthquake derived from low-gain seismograms
}

\author{
Masayuki Kikuchi ${ }^{1}$, Misao Nakamura ${ }^{2}$, and Kazumitsu Yoshikawa ${ }^{3}$ \\ ${ }^{1}$ Earthquake Research Institute, University of Tokyo, 1-1-1 Yayoi, Bunkyo-ku, Tokyo 113-0032, Japan \\ ${ }^{2}$ Information Service for Disaster Prevention, 230-7 Miroku-cho, Sakura, Chiba 285-0038, Japan \\ ${ }^{3}$ Seismological and Volcanological Department, Japan Meteorological Agency, 1-3-4 Otemachi, \\ Chiyoda-ku, Tokyo 100-0004, Japan
}

(Received October 7, 2002; Revised March 19, 2003; Accepted March 19, 2003)

\begin{abstract}
In the 1940's, several destructive earthquakes occurred in western Japan. Seismograms in this period were usually recorded on smoked paper and the quality was poor compared to modern digital data. But the recent development of image processing technology enabled us to reconstruct feasible waveform data, whereby we investigated source rupture processes of two devastating earthquakes: the Tonankai earthquake (M7.9) of December 7, 1944, and the Mikawa earthquake (M6.8) of January 13, 1945. The results for the Tonankai earthquake show that the source roughly consists of a single asperity with a length scale of $100 \mathrm{~km}$, having no segment structure with a smaller length-scale. Such a feature seems to be reflected to the sea bottom topography above the source region. The main source parameters are as follows: the seismic moment $=1.0 \times 10^{21} \mathrm{Nm}(\mathrm{Mw}=7.9)$; the fault area $=140$ $\mathrm{km} \times 80 \mathrm{~km}$; (strike, dip, rake $)=\left(225^{\circ}, 15^{\circ}, 79^{\circ}\right)$; the maximum and averaged dislocations $=4.4 \mathrm{~m}$ and $3.0 \mathrm{~m}$, respectively. The analysis of the seismograms for the Mikawa earthquake shows that the source is a reverse fault with a slight left-lateral component. The pressure axis is directed to ENE-WSW, which is a little rotated from the EW compression axis prevailing in western Japan. This fault can be regarded as the southern extension of the Nobi earthquake fault system. The main source parameters are as follows: the seismic moment $=1.0 \times 10^{19} \mathrm{Nm}$ $(\mathrm{Mw}=6.6)$; the fault area $=20 \mathrm{~km} \times 15 \mathrm{~km}$; (strike, dip, rake $)=\left(135^{\circ}, 30^{\circ}, 65^{\circ}\right)$; the maximum and averaged dislocations are $2.1 \mathrm{~m}$ and $1.1 \mathrm{~m}$, respectively. The slip distribution mainly consists of two asperities: the one near the hypocenter and the other $10-15 \mathrm{~km}$ northwest from it. The heavily damaged area is well correlated with the northwestern asperity.
\end{abstract}

Key words: Asperity, source process, source parameters, devastating earthquake, historical seismograms.

\section{Introduction}

Most earthquakes are caused by rapid shear faulting within underground bedrock subject to tectonic stress. The faulting expands, on average, at a speed of $2-3 \mathrm{~km} / \mathrm{s}$. The propagation is usually irregular, and the slip motion is rather heterogeneous over the fault plane. The amount of slip is not necessarily large near the initial break (hypocenter), but tends to increase further from the epicenter. Such a large slip area is called an "asperity" on the fault plane. The asperity is characterized by an area where the interface strongly sticks during the inter-seismic period, and then abruptly slips at a certain instant to generate seismic waves. It has been clarified that the size and distribution of the asperity controls not only the seismicity pattern, such as the sequence of foreshocksmain shock-aftershocks, but also the distribution of strong ground motion.

The location and size of the asperity can be identified by the analysis of seismic records. If the asperity changes its location at each earthquake, the information on the asperity for a specific event would not be very valuable for assessing another future event. Fortunately, however, this is not the ac-

Copy right(C) The Society of Geomagnetism and Earth, Planetary and Space Sciences (SGEPSS); The Seismological Society of Japan; The Volcanological Society of Japan; The Geodetic Society of Japan; The Japanese Society for Planetary Sciences. tual case. Recent studies (e.g. Nagai et al., 2001; Yagi and Kikuchi, 2003) have made it clear that there are characteristic sites which are partitioned for asperities. Therefore, any knowledge we can gain of the asperity of past earthquakes will be very useful for estimating how future earthquakes may occur. From this viewpoint, we have searched for historical seismograms of past large earthquakes, and analyzed them to obtain the asperity distribution for individual earthquakes.

In the 1940's, several devastating earthquakes, which resulted in death tolls of over 1,000 persons, occurred in Japan. These earthquakes include the 1943 Tottori earthquake (M7.2), the 1944 Tonankai earthquake (M7.9), the 1945 Mikawa earthquake (M6.8), the 1946 Nankai earthquake (M8.0), and the 1948 Fukui earthquake (M7.1). In this paper, we investigate two of these earthquakes in western Japan: the Tonankai earthquake and the Mikawa earthquake.

\section{Historical Seismograms}

Nearly a century has passed since modern instrumental observation was begun in Japan. During this period, dozens of earthquakes larger than the M7 class occurred throughout Japan. The seismograph data were recorded and preserved, mainly at the Japan Meteorological Agency (JMA), with some records kept at several universities. Most of the data 
before the 1970's are analog records on smoked paper, so the quality is poor compared to modern, high-quality digital seismograms. However, owing to the recent development of image processing technology, these historical seismograms can now be more easily treated to be used in earthquake source studies.

The JMA has compiled the historical records on these earthquakes by taking microfilms, which are available for viewing by general users, and the original seismograms of especially important events have also been preserved. We took raster data of the microfilms with a scanner, digitized the wave traces on a PC screen, and stored the vector data in the file. The great advantage of this digitization system is that we can check the accuracy of the vector data to the original wave traces directly on the enlarged screen. Digitizing can be improved on the screen by adding sampled points, if the shape of the wave traces cannot be reproduced well.

The wave traces were next corrected for the arc effect due to the finite length of the pen arm, and for the bias of the balance point, following the method by Kikuchi et al. (1999). The records were then converted into digital data with a $0.05 \mathrm{~s}$ sampling time, and bandpassed between 0.01 and $1 \mathrm{~Hz}$ to obtain digital data with a $0.5 \mathrm{~s}$ sampling time. The effective spectral range of observed records is roughtly $0.05-0.5 \mathrm{~Hz}$.

The chart speed was often unclear in the historical seismograms. When the chart speed was unclear, we gathered as much information from the literature as possible on the instrumental characteristics. It should be noted here that even the polarity of three components noted on the seismograms is sometimes incorrect, and, therefore, we always have to verify it by the compatibility between the $P$ wave polarity and the ray-direction.

\section{Waveform Inversion}

Let us here describe the inversion method. First, we calculate the Green's functions, namely, the synthetic waveforms generated from the unit source-elements at grid points. We use the computer code by Koketsu (1985) based on the improved reflectivity method for calculating wave fields in horizontal layered structures. There are several input parameters for the calculation as given in (1)-(3).

\section{(1) Grid scheme on the fault plane}

We use a certain hypocenter and mechanism solution given in the literature to construct the grid scheme. The hypocenter is assumed to be the rupture initiation point, and the grid points are placed on the fault plane by $N_{x}$ points at an interval of $\Delta x$ along the fault strike, and $N_{y}$ points at an interval of $\Delta y$ along the dip direction. The serial number is put on the grid of $p$-th in the fault strike, and $q$-th in the dip direction, as:

$$
g=p+(q-1) N x \quad p=1,2, \ldots, N_{x} ; \quad q=1,2, \ldots, N_{y}
$$

\section{(2) Seismograph characteristics}

In the present inversion, we use the records of seismographs as the observed data, and accordingly the Green's function contains the instrumental response. The characteristic constants of the seismographs, such as the pendulum period and attenuation coefficient, are adjusted within an allow- able range by inspecting the features of the observed waveforms.

\section{(3) Underground structure}

A semi-infinite stratified structure is given by the literature. It is assumed that the structure is common to all of the observation points.

Next, we formulate synthetic waveforms in terms of Green's functions weighted by unknown parameters. Let $G_{g k j}(t)$ be the Green function for the $j$-th record generated from the fault slip toward the $k$-th direction $(k=1,2)$ with the unit moment, and the moment rate function of $2 \tau$ wide isosceles at the $g$-th grid. Superposing the $N_{h}$ isoscele moment rate functions numbered $h=1, \ldots, N_{h}$ with a time shift of $\tau$, the synthetic waveform is given by

$$
y_{j}(t)=\sum_{g} \sum_{h} \sum_{k} D_{g h k} G_{g k j}\left(t-t_{g}-(h-1) \tau\right)
$$

where $D_{g h k}$ represents the unknown model parameters, and $t_{g}$ is the start time of the fault motion at the $g$-th grid. Let $V$ denote the rupture front velocity, and $\left(p_{0}, q_{0}\right)$ the grid at the initial break point. The rupture start time at the $g$-th grid is then given by

$$
t_{g}=\left[\left\{\left(p-p_{0}\right) \Delta x\right\}^{2}+\left\{\left(q-q_{0}\right) \Delta y\right\}^{2}\right]^{1 / 2} / V
$$

This does not necessarily constrain the rupture pattern to a circular expansion, because the rupture time at each grid is allowed to vary within an interval of $N_{h} \tau$. The least squares error criterion is then represented by

$$
\Delta=\sum_{j} \int w_{j}\left\{x_{j}(t)-y_{j}(t)\right\}^{2} d t=\text { minimum }
$$

where $x_{j}(t)$ denotes the $j$-th observed data, and $w_{j}(>0)$ is the relative weight factor for the $j$-th record.

We here impose two constraints on the least squares criterion. One is the range of the fault slip vector. We assume that the direction of the slip vector is restricted within $\pm 45^{\circ}$ around a certain given value $\lambda_{0}$. This can be realized as follows. The slip vector is decomposed into two components with slip angles of $\lambda_{0}+45^{\circ}$ and $\lambda_{0}-45^{\circ}$, and the condition of "Non-negative" is imposed on each element. The other constraint is the smoothness of the spatial distribution of the fault slip. Following Yoshida (1995) and Yagi et al. (1999), the degree of smoothness is defined by a digital Laplacian:

$$
\nabla^{2} D_{g}=4 D_{g}-D_{g-1}-D_{g+1}-D_{g-N_{x}}-D_{g+N_{x}}
$$

where we omitted the subscript $h k$ of $D_{g h k}$. Adding the sum of the square of (5) to the relation (4) gives the objective function that should be minimized. That is,

$$
\Delta^{\prime}=\Delta+\beta^{2} \sum_{g}\left\{\nabla^{2} D_{g}\right\}^{2}=\text { minimum }
$$

In the above, we do not consider the smoothness in time domain, so that the complexity of rupture propagation may be reflected to the moment rate function at each grid. For the computer code, it is convenient to put serial numbers both 


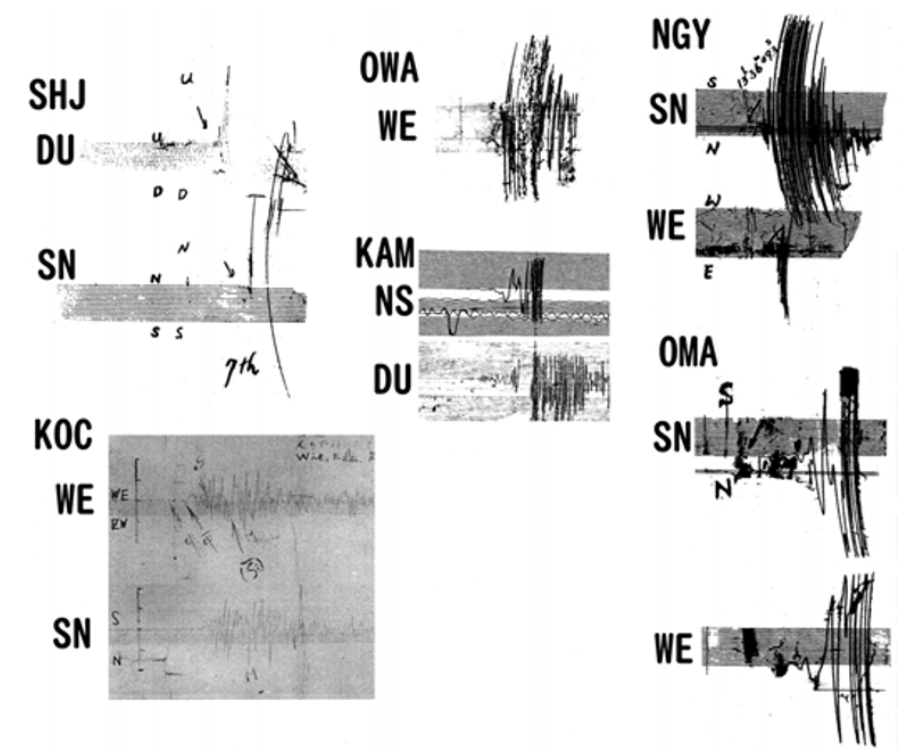

Fig. 1. Original records of the low-gain seismographs for the 1944 Tonankai earthquake (M7.9) at JMA stations. The reduced scale is arbitrary for each record. All of the wave traces except at KOC are clipped off soon after the $P$ or $S$ or surface wave arrivals.

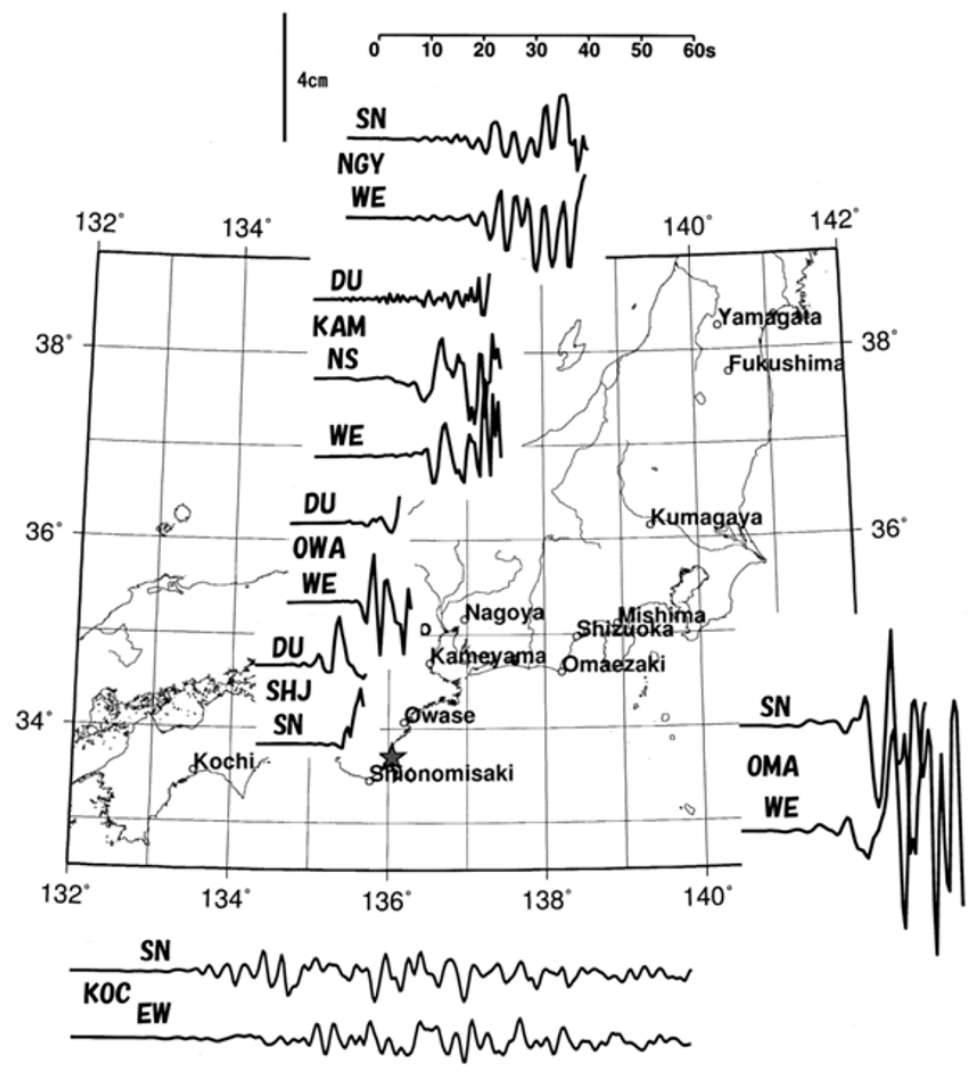

Fig. 2. Digitized waveforms of the 1944 Tonankai earthquake. The amplitude and the time axes are adjusted to the common scale. The star indicates the epicenter of the initial break used in the present inversion.

for the model parameters and for the observed data points. The serial number for the model parameters is given by

$$
\begin{gathered}
m=g+(h-1) N_{g}+(k-1) 2 N_{g} \\
g=1,2, \ldots, N_{g} ; \quad h=1,2, \ldots, N_{h} ; \quad k=1,2
\end{gathered}
$$

where $N_{g}=N_{x} N_{y}$ is the number of grid points. The total number of the model parameters is $N_{m}=2 N_{g} N_{h}$. The serial number for the sampled data $x_{j}(\Delta t(i-1))$ is put as $x_{n}=x_{j}(\Delta t(i-1))$ by

$$
n=i+\left(N_{1}+N_{2}+\cdots+N_{j-1}\right) \quad i=1,2, \ldots, N_{j}
$$

where $N_{j}$ denotes the number of data at the $j$-th record.

Now the objective function can be represented in a simple 


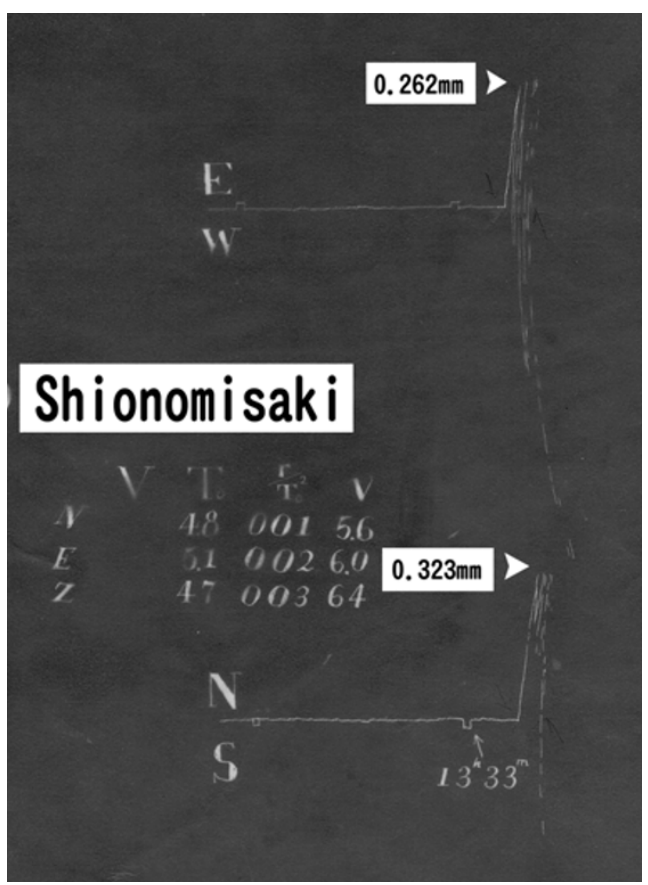

Fig. 3. Horizontal components of the seismic records by Wiechert-type seismograph at Shionomisaki (SHJ). The initial peak values of ground motions are referred to Seismological Bulletin of CMO of Japan (1944).

form as

$$
\begin{aligned}
\Delta^{\prime}= & \sum_{n}\left\{\sum_{m} G_{n m} D_{m}-x_{n}\right\}^{2} \\
& +\beta^{2} \sum_{m}\left\{\sum_{m^{\prime}} L_{m m^{\prime}} D_{m^{\prime}}\right\}^{2}=\text { minimum }
\end{aligned}
$$

where $G_{n m}$ and $L_{m m^{\prime}}$ denote the Green function and the digital Laplacian operator, respectively. The value of $\beta$ defines the degree of smoothness, so that the larger the $\beta$, the smoother the solution that is obtained. In the following, we use the normalized parameter $\beta_{0}$ instead of $\beta$ as follows:

$$
\beta=\beta_{0} \sqrt{\left(\sum_{n} \sum_{m} G_{n m}^{2}\right) /\left(\sum_{m} \sum_{m^{\prime}} L_{m m^{\prime}}^{2}\right)}
$$

Some statistical criterion such as ABIC (Akaike's Bayesian Information Criterion) (Akaike, 1980) might be used for the value of $\beta$. However, we here determine $\beta$ by inspecting whether the synthetic waveforms restore distinct phases of the observed waveforms.

While analyzing the low-gain historical seismograms, we often encounter a troublesome difficulty in the time correction, due to poor time-precision. We here make a rough adjustment based on the $P$ wave and/or $S$ wave arrivals, and then vary the time axis within a certain allowable range, say $\pm 5 \mathrm{sec}$ in the waveform inversion. Note that in this treatment, the information on the hypocenter is very important, affecting the result of spatial distribution of moment release.

4. The Tonankai Earthquake of December 7, 1944

This earthquake occurred at 13:35 local time (04:35 UT) on December 7, 1944, and was felt in a broad area, with a maximum radius of $620 \mathrm{~km}$ (Seismological Bulletin of the Central Meteorological Observatory (CMO) of Japan, 1944). A tsunami with a height of 8-10 m struck the coast of Kumano-nada. The earthquake and the tsunami caused totally 1,223 people killed or declared missing, and 17,347 houses destroyed in Shizuoka, Aichi, and Mie prefectures (Utsu, 1987). Many source models have been proposed for this earthquake by long-period surface waves (Kanamori, 1972), geodetic data (Yabuki and Matsu'ura, 1992), tsunami data (Satake, 1993; Tanioka and Satake, 2001), and local and global seismic data (Ichinose et al., 2003).

Figure 1 shows the JMA strong motion seismograms used in the present analysis. The seismograms at KOC (Kochi) were recorded by Imamura's seismograph, and the others by CMO strong motion seismograph. Both are mechanical seismographs of low-gain displacement type. The instrumental constants, as well as the station parameters, are given in Table 1. We discovered that at SHJ (Shionomisaki), the polarities written on the seismograms as UD/NS/EW are incorrect. The correct polarities are DU/SN/WE. The staff of the JMA later noticed this after inspecting the other seismograms at SHJ. Figure 2 shows the digitized records corrected for the arc effects and the magnification. Since the pendulum period is nearly the same for all records in Figure 2, the amplitude and the shape of waveforms can be evenly compared.

The star indicates the epicenter: $\left(33.70^{\circ} \mathrm{N}, 136.05^{\circ} \mathrm{E}\right)$ given by Kanamori (1972). We adopted this epicenter as the initial break. For confirming the location of the epicenter, the polarities of the $P$ wave initial motion at SHJ and OWA (Owase) were useful. According to the Seismological Bulletin of $\mathrm{CMO}$, the $P$ wave polarity is directed to $\mathrm{N} 39^{\circ} \mathrm{E}$ at $\mathrm{SHJ}$ and $\mathrm{S} 2{ }^{\circ} \mathrm{W}$ at OWA. Figure 3 shows the horizontal components recorded by the Wiechert seismograph at SHJ. Kanamori's epicenter was very consistent with this polarity. The hypocenter was put at depth $h_{0}=30 \mathrm{~km}$ considering the plate interface. We adjusted the observed $P$-wave and/or $S$-wave arrivals to the theoretical ones calculated for this hypocenter.

As seen in Figure 2, the time at which the records were clipped is shifted in the order of SHJ, OWA, KAM (Kameyama), and NGY (Nagoya). Moreover, the amplitude of the record at OMA (Omaezaki) is several times as large as that of the record at KOC, the epicentral distance of which is nearly equal to OMA. Such a feature strongly suggests that the rupture started near SHJ, and propagated towards the northeast.

Since most of the records near the source region were clipped off about $30 \mathrm{~s}$ after the origin time, we have to rely on the records at OMA and KOC for estimating the fault motion at a later stage. Under such poor observational conditions, the setting of a too wide fault area cannot produce a significant result. Because of this, we restricted the available fault area to a necessarily minimum range that can reproduce the observed records.

Table 1 summarizes the various parameters used for the inversion. We assumed the fault strike, $\mathrm{N} 225^{\circ} \mathrm{E}$, parallel to the slab interface at the source depth, and the dip angle of $15^{\circ}$ following Kanamori (1972). The characteristics of the seismograph (pendulum period, magnification and damping coefficient) were based on the values noted on the seismo- 
Table 1. Source information and station parameters for the 1944 Tonankai earthquake used in the present inversion.

(a) Source information

Origin Time: 1944/12/07 04:35 UT

Epicenter: $33.70^{\circ} \mathrm{N} 136.05^{\circ} \mathrm{E} \quad$ Depth: $30 \mathrm{~km}$

\begin{tabular}{|c|c|c|c|c|c|c|c|}
\hline Station & Code & $\Delta[\mathrm{km}]$ & $\phi_{a}\left[{ }^{\circ}\right]$ & $T_{p}[\mathrm{~s}]$ & $T_{S}[\mathrm{~s}]$ & \multicolumn{2}{|c|}{ Comp. $\left(T_{0}[\mathrm{~s}], \mathrm{h}\right)$} \\
\hline Shionomisaki & SHJ & 38.6 & 223.6 & 8.0 & 14.2 & $\mathrm{SN}(4.3,0.2)$ & DU $(4.8,0.1)$ \\
\hline Owase & OWA & 42.9 & 18.1 & 8.5 & 15.2 & WE $(3.0,0.1)$ & DU $(4.8,0.1)$ \\
\hline Kameyama & KAM & 134.2 & 16.4 & 20.1 & 35.7 & NS $(5.0,0.1)$ & DU $(2.3,0.2)$ \\
\hline Nagoya & NGY & 183.4 & 27.1 & 26.2 & 46.6 & $\mathrm{SN}(5.0,0.2)$ & WE $(5.0,0.1)$ \\
\hline Omaezaki & OMA & 223.3 & 62.7 & 31.2 & 55.5 & $\mathrm{SN}(5.0,0.2)$ & WE $(5.0,0.2)$ \\
\hline Kochi & $\mathrm{KOC}$ & 233.2 & 266.7 & 32.5 & 57.7 & $\mathrm{SN}(6.6,0.2)$ & $\operatorname{EW}(6.3,0.2)$ \\
\hline
\end{tabular}

$\Delta=$ Epicentral distance; $\phi_{a}=$ Azimuth; $T_{p}, T_{s}=$ Theoretical $P-, S$-wave travel time; $T_{0}=$ Period of pendulum,

$h=$ Damping constant

\begin{tabular}{cccccc} 
(c) Underground structure & & & \\
\hline$V_{p}[\mathrm{~km} / \mathrm{s}]$ & $V_{s}[\mathrm{~km} / \mathrm{s}]$ & $\rho[\mathrm{g} / \mathrm{cm} 3]$ & $D[\mathrm{~km}]$ & $Q_{P}$ & $Q_{S}$ \\
\hline 5.50 & 2.80 & 2.30 & 4 & 250 & 500 \\
6.10 & 3.40 & 2.70 & 16 & 250 & 500 \\
6.60 & 3.80 & 2.88 & 11 & 250 & 500 \\
8.00 & 4.50 & 3.27 & $\infty$ & 250 & 500 \\
\hline \multicolumn{7}{l}{$V_{p}, V_{s}=P$ - and $S$-wave velocity; $\rho$ = Density; $D=$ Thickness; $Q_{P} Q_{S}=$ quality }
\end{tabular}

factor for $P$ and $S$

grams or reported in the literature (Hamamatsu, 1966), and adjusted within an allowable range, say, $\pm 1 \mathrm{~s}$ for the pendulum period. The final values for the instrumental constants used in the present analysis are shown in Table 1(b). The underground structure used to calculate Green's functions is given in Table 1(c). This structure is based on the $P$-wave crustal structure in the western part of Japan by Yoshii et al. (1974), and the $V_{p} / V_{s}$ structure by Ichikawa and Mochizuki (1971).

We first placed a narrow grid scheme $(40 \mathrm{~km} \times 40 \mathrm{~km})$ on the fault plane to carry out the waveform inversion. The discretization parameters for fault plane and moment-rate function were given as follows:

$$
\Delta x=\Delta y=20 \mathrm{~km}, \quad \tau=1.5 \mathrm{~s}, \quad N_{h}=10 .
$$

Figure 4 shows the result. The records at SHJ and OWA are well reconstructed only by the contribution from this small fault area, while the records at the other stations are not explained well. In a similar way, the fault slip within the area of $80 \mathrm{~km} \times 80 \mathrm{~km}$ could restore the waveforms at most stations, but the amplitude of the synthetic records at OMA were yet too small compared with the observed ones. Finally, it turned out that the fault slip over the range of $140 \mathrm{~km} \times 80 \mathrm{~km}$ was sufficient to explain the entire shape of the waveforms. The waveform match between the observed and the synthesized was no longer improved so much by the addition of the grid points on a wider area of the fault plane. The rupture front velocity was searched within 2.5$3.5 \mathrm{~km} / \mathrm{s}$ with an increment of $0.1 \mathrm{~km} / \mathrm{s}$ and the best-fit value was found to be $V=3.1 \mathrm{~km} / \mathrm{s}$.

Let us here briefly note the effect of the smoothness constraint. In general, the larger $\beta$ in relation (9) results in the more smooth slip distribution and the worse waveform match between the observed and the synthesized seismograms. The resultant slip distribution and waveform comparison at NGY for various $\beta_{0}$ are shown in Figure 5. We can see that the waveform match is good enough for $\beta_{0} \leq 0.1$, but that $\beta_{0}=0.001$ results in an unlikely, complicated pattern of slip distribution. Thus, we adopted the case of $\beta_{0}=0.05$ as the final solution.

\subsection{Results}

Figure 6 shows the final fault model. The main source parameters are given in Table 2 . The rake varied slightly from the initial value, but was largely unchanged during the source process. Figure 7 shows the moment release rate obtained at each grid point. We can see a considerable high frequency component in the time function. Since moment rate is given by the convolution of the dislocation velocity and the rupture area expansion rate, we can interpret the results in terms of the complexity of the dislocation and/or the rupture propagation within a corresponding fault cell. Figure 8 shows the comparison between the observed and the synthetic seismograms. The main features of the moment release process are as follows.

(1) A large fault slip was obtained over the fault plane off Kumano-nada. The fault area is estimated to be about $S=$ $140 \mathrm{~km} \times 80 \mathrm{~km}$.

(2) The maximum dislocation, $D_{m}=4.4 \mathrm{~m}$, appeared about $120 \mathrm{~km}$ northeast from the epicenter, off Shima Peninsula. The average dislocation is $D_{a}=M o / \mu S=3.0 \mathrm{~m}$, where the total seismic moment $M o=1.0 \times 10^{21} \mathrm{Nm}$ and the average rigidity is $\mu=30 \mathrm{GPa}$.

(3) The total duration of the source rupture process is about $60 \mathrm{~s}$.

(4) The stress drop is $\Delta \sigma=2.5 \mathrm{Mo} / \mathrm{S}^{1.5}=2.1 \mathrm{MPa}$. This value is roughly within a range of typical values for shallow subduction zone earthquakes (Kanamori and Anderson, 1975). 
(a)

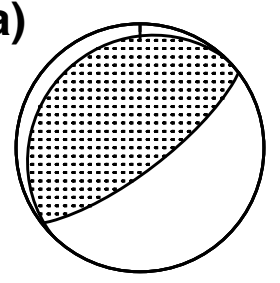

(b) $\quad$ Mw 7.4

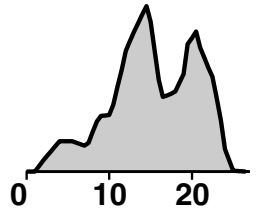

$(225,15,83)$

(c)

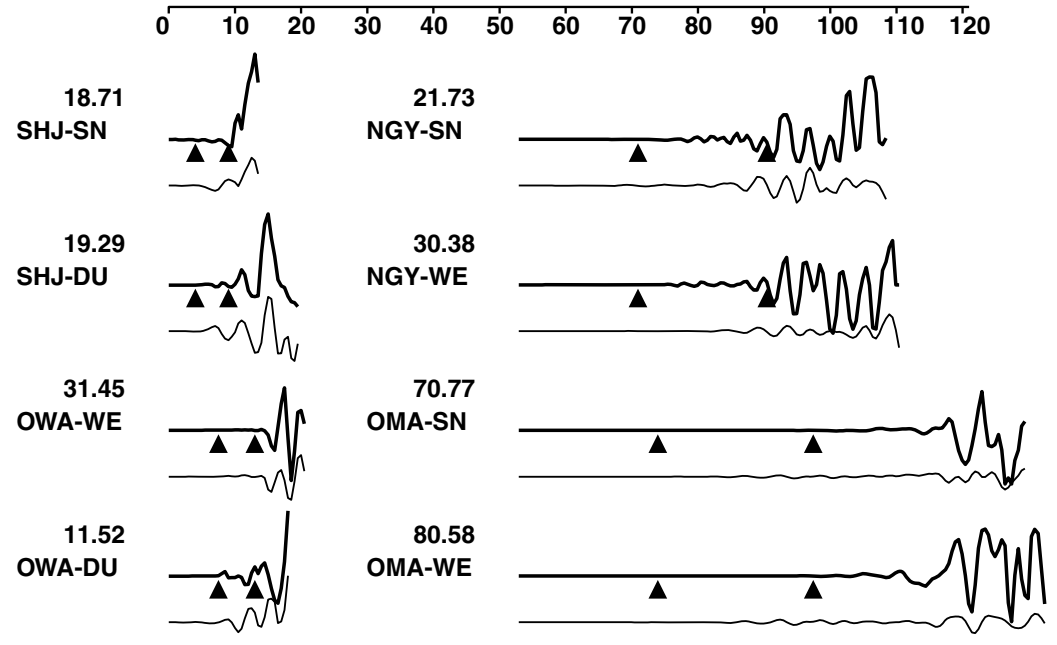

13.42
KAM-DU

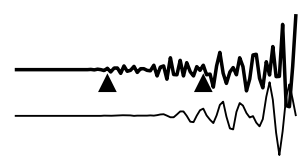

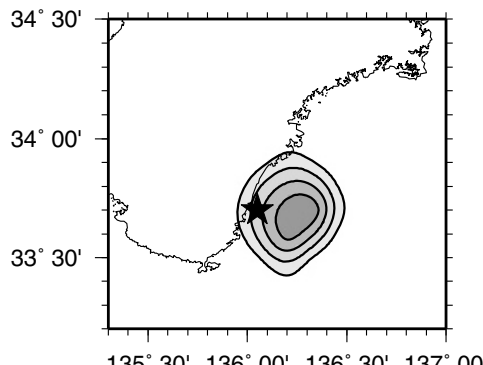

$135^{\circ} 30^{\prime} 136^{\circ} 00^{\prime} 136^{\circ} 30^{\prime} 137^{\circ} 00^{\prime}$

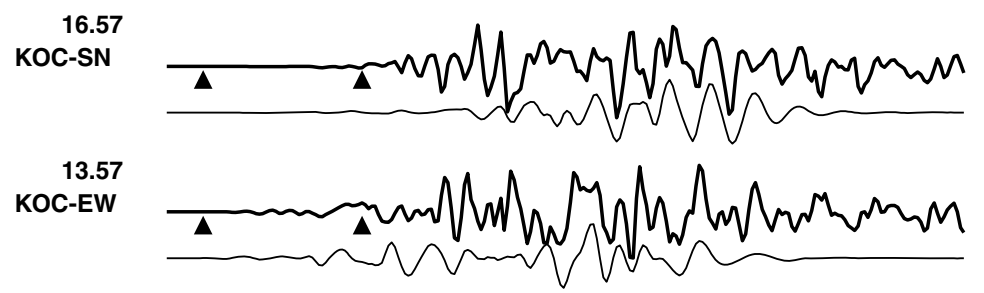

Fig. 4. Result of waveform inversion where the slip area is confined to a narrow part ( $40 \mathrm{~km} \times 40 \mathrm{~km})$ of the fault plane as shown in a map view. (a) Mechanism solution; (b) Moment rate function; (c) Comparison of waveforms between the observed (upper trace) and the synthetic (lower trace) ones. The number above the station code denotes the peak-to-peak value $[\mathrm{mm}]$ of the observed wave. Solid triangles indicate theoretical $P$ - and $S$-wave arrivals. The travel times are given in Table 1(b).

\subsection{Rupture extent}

The extent of the source area is a key information in determining the focus of the target area for the national project for Tokai earthquake prediction. The basic idea of this project is that the area, which was ruptured during the 1854 Tonankai earthquake (Ansei Tokai earthquake) but unruptured in the 1944 Tonankai earthquake (Showa Tonankai earthquake), will be a source area of the forthcoming Tokai earthquake. Based on the assumed source model, the ground mo-
Table 2. Source parameters obtained in the present study.

\begin{tabular}{ll}
\hline Fault mechanism & $($ Strike, Dip, Rake $)=\left(225^{\circ}, 15^{\circ}, 79^{\circ}\right)$ \\
Seismic moment & Mo $=1.0 \times 10^{21} \mathrm{Nm} \quad \mathrm{Mw}=7.9$ \\
Fault area & $S=140 \mathrm{~km} \times 80 \mathrm{~km}$ \\
Fault slip Maximum & $D_{m}=4.4 \mathrm{~m}$ \\
\multicolumn{1}{c}{ Average } & $D_{a}=3.0 \mathrm{~m}$ \\
Stress drop & $\Delta \sigma=2.1 \mathrm{MPa}$ \\
Rupture front velocity & $V=3.1 \mathrm{~km} / \mathrm{s}$ \\
\hline
\end{tabular}


$(5.0,18857,0.6168)$
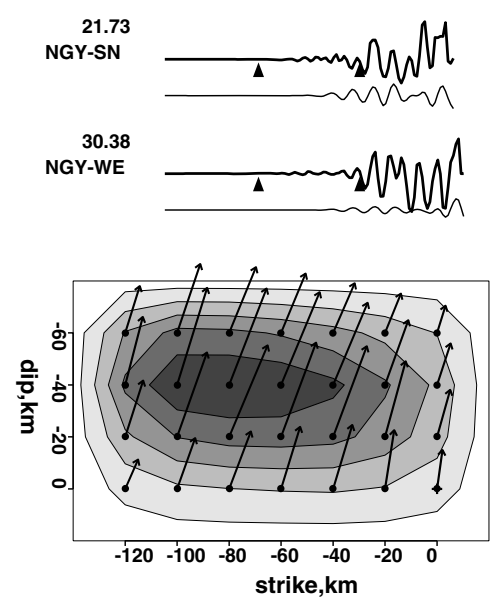

$(0.05,18520,0.2340)$
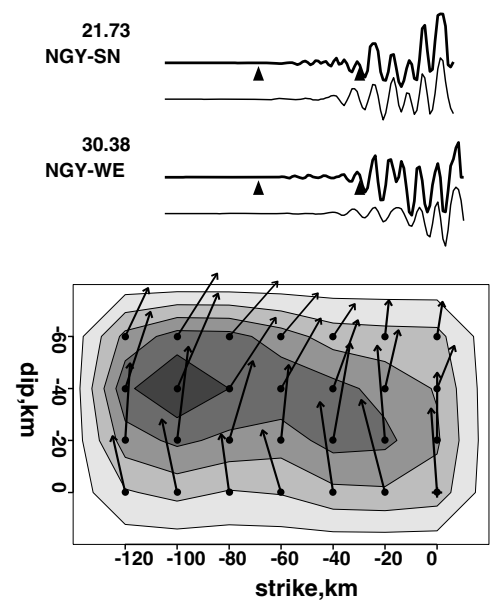

$(0.5,18523,0.4040)$
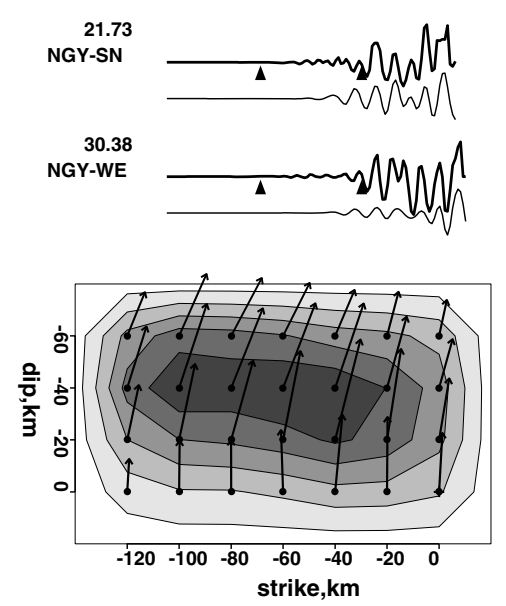

$(0.001,19526,0.1312)$
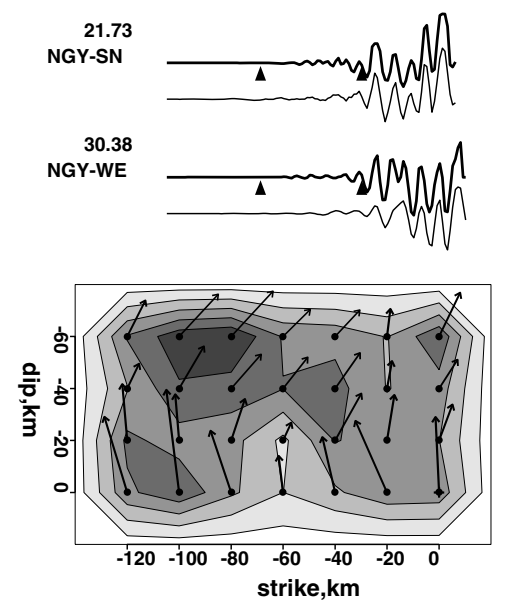

Fig. 5. Slip distribution obtained for various values of the smoothness coefficient, $\beta_{0}$, and the waveform comparison at NGY. The numbers in parentheses denote, in order, $\beta_{0}, \mathrm{ABIC}$, and variance. The case of $\beta_{0}=0.05$ is selected as the final solution.

tion was simulated by computer, and areas where destructive strong-motion is expected, were determined. Following this determination, the national government offers financial support to local governments to prepare for disaster mitigation. Because of this, the source area of the 1944 Tonankai earthquake is of a special interest not only to scientists, but also to local governments.

The present analysis suggests that the source rupture occurred mainly off Kumano-nada, although a further extension of rupture toward northeast cannot be excluded. This feature is consistent with findings from the previous studies mentioned above. The slip distribution, especially, is in good agreement with the result by Tanioka and Satake (2001), which indicates a larger slip off Shima Peninsula.

\subsection{Seismic moment and possible slow slip}

The seismic moment, as estimated from the surface wave data, geodetic data, and tsunami data, is about $2 \times 10^{21} \mathrm{Nm}$ (Kanamori, 1972; Inouchi and Sato, 1975; Aida, 1979; Tanioka and Satake, 2001). The seismic moment obtained in the present analysis is $M o=1.0 \times 10^{21} \mathrm{Nm}$, only one half of the previous estimation. However, a large part of the discrepancy may be due to the different values assumed for the rigid- ity $\mu$. In most of the papers cited above, the value $\mu=50$ GPa was used, while in our structure model, the source region is within the crust and $\mu=18$ to $42 \mathrm{GPa}$, the average being $30 \mathrm{GPa}$. Since the basic quantity in the analysis of the geodetic data and tsunami data is the dislocation, the seismic moment is proportional to an assumed value for the rigidity. Therefore, the previous estimate is reduced to $1.3 \times 10^{21} \mathrm{Nm}$ without any change in the tsunami data analysis if $\mu=30$ GPa is used.

There is another interpretation that the difference in the moment estimate is still significant, and that it may come from a more intrinsic source process, that is, the wide spectral contents of the fault motion. It seems likely that the strong motion records reflect the much shorter period component of the fault slip than that affecting the tsunami generation. Kato and Ando (1997) analyzed the tsunami data considering the finite rise time of the crustal motion, and found that a large tsunami with a rise time of as long as a few minutes was excited around the Atsumi peninsula. This region is just outside the coseismic slip region (asperity) obtained in the present analysis. It is interesting to note that aseismic fault slip occurred near Hamana Lake (close to Atsumi 
(a)

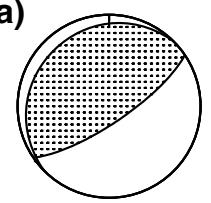

(b) $\quad$ Mw 7.9

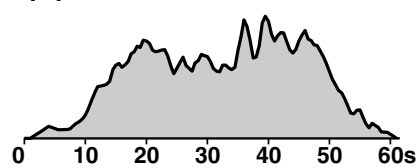

$(225,15,79)$

(c)

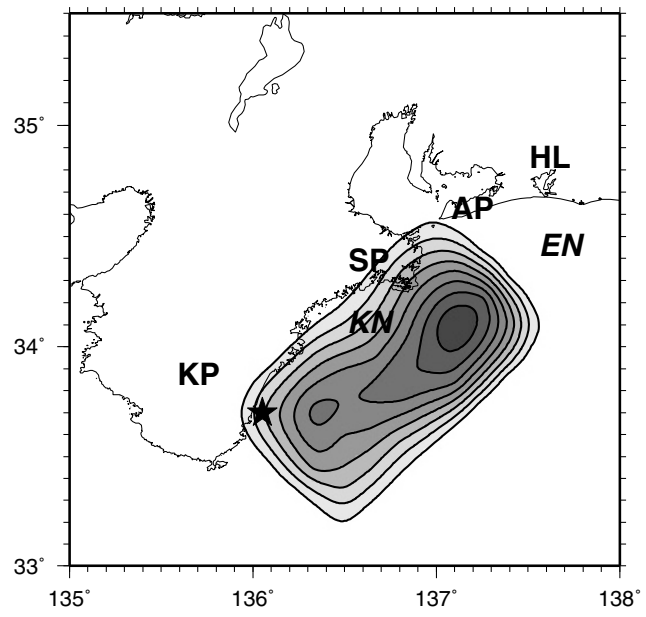

Fig. 6. Final solution of the 1944 Tonankai earthquake. (a) Mechanism solution; (b) Moment-rate function; (c) Map view of the fault slip. The increment of contour lines is 0.5 m. KP: Kii Peninsula; KN: Kumano-nada; SP: Shima Peninsula; AP: Atsumi Peninsula: HL: Hamana Lake; EN: Enshu-nada.

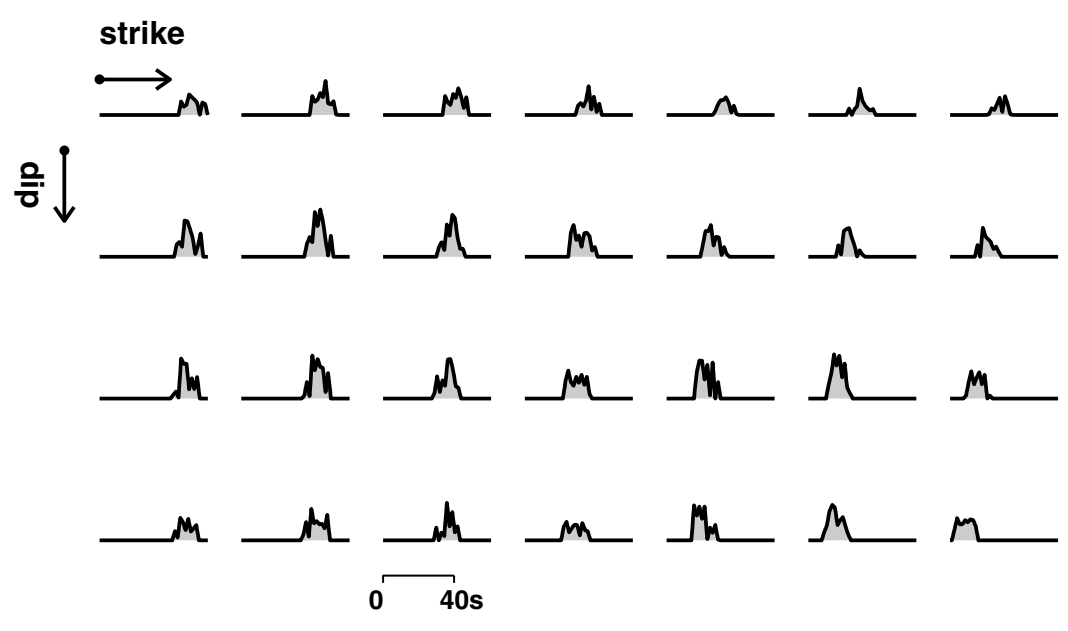

Fig. 7. Moment release rate at all grid points obtained for the 1944 Tonankai earthquake. The initial break (hypocenter) locates at a corner of the rightmost and bottom.

Peninsula) and continued for over a year (G. S. I., 2002).

\subsection{Asperity distribution}

As seen in Figure 6, the fault slip distribution extends to about $140 \mathrm{~km}$ in length off Kumano-nada. The source consists of mainly a single large asperity. In other words, there is no segment structure with a length scale of the M7 class earthquake, say of $30 \mathrm{~km}$ or so. In this region we may therefore expect only an M8 class earthquake to occur, or only small earthquakes less than or equal to M6.

In contrast, the Hyuga-nada region is accompanied by several asperities of the M7 class earthquakes, each being isolated far apart. In this region, therefore, we may expect that more than one asperities will not synchronize rupturing at the same time, and, consequently, the maximum size of any earthquakes that occur in this region will remain within the M7 class. In fact, there is no historical record of any M8 class earthquake occurring in this region.

Another distinct pattern of the asperity distribution was obtained in the off-Sanriku district. Nagai et al. (2001) examined the source processes of the 1968 Tokachi-oki earthquake and the 1994 Sanriku-oki earthquake, and proposed that there are characteristic sites for asperities with the length scales of M7 class earthquake, and that the individual asperities manifest M7 class earthquakes, but sometimes synchronize to cause an M8 class earthquake. Thus, the maximum earthquake size and the seismicity pattern in each region are closely related to the distribution of the asperity. A schematic illustration is given in Figure 9. 

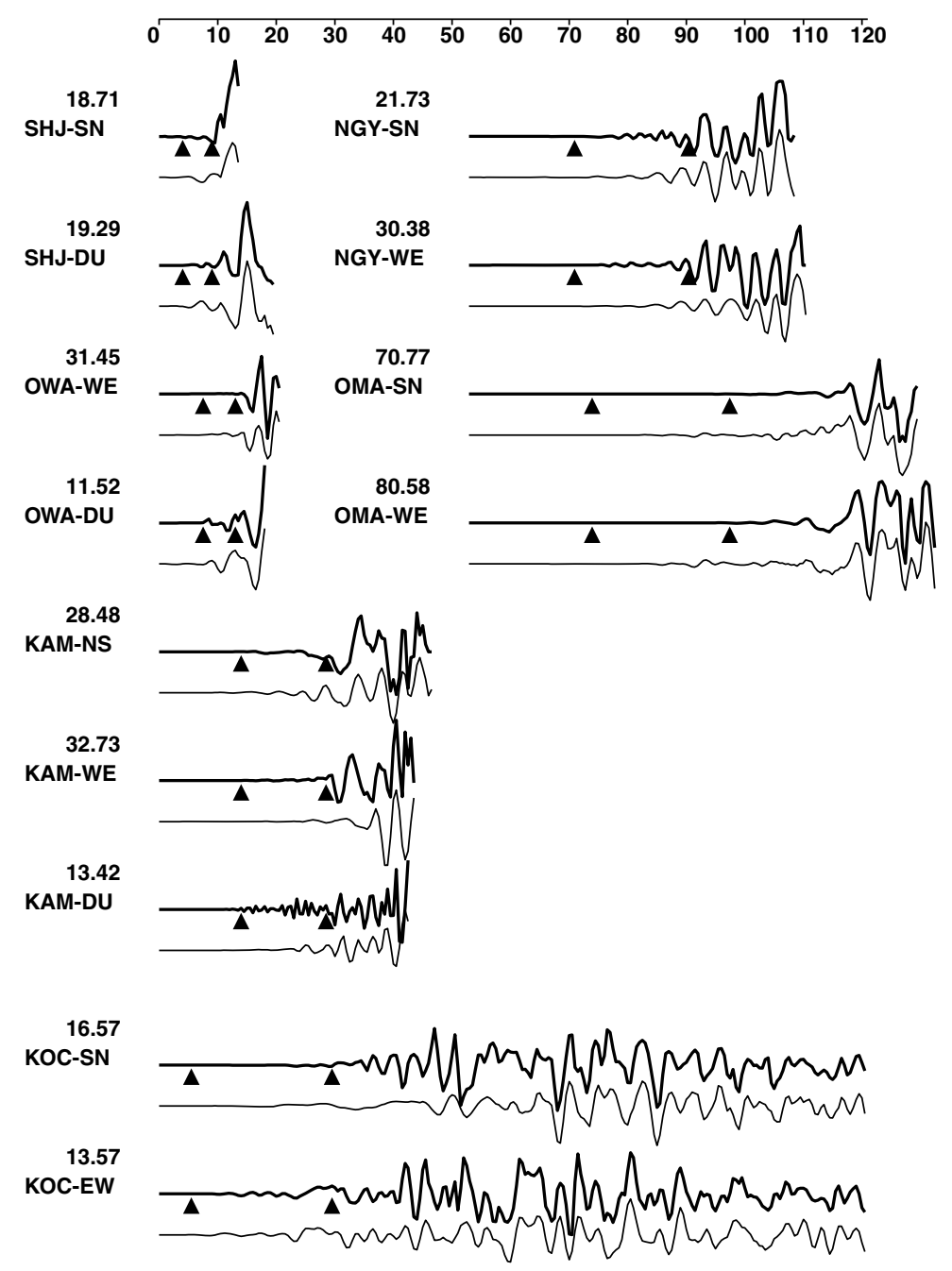

Fig. 8. Comparison of waveforms between the observed (upper trace) and the synthesized (lower trace) in the 1944 Tonankai earthquake. For the notation, see caption of Figure 4(c).

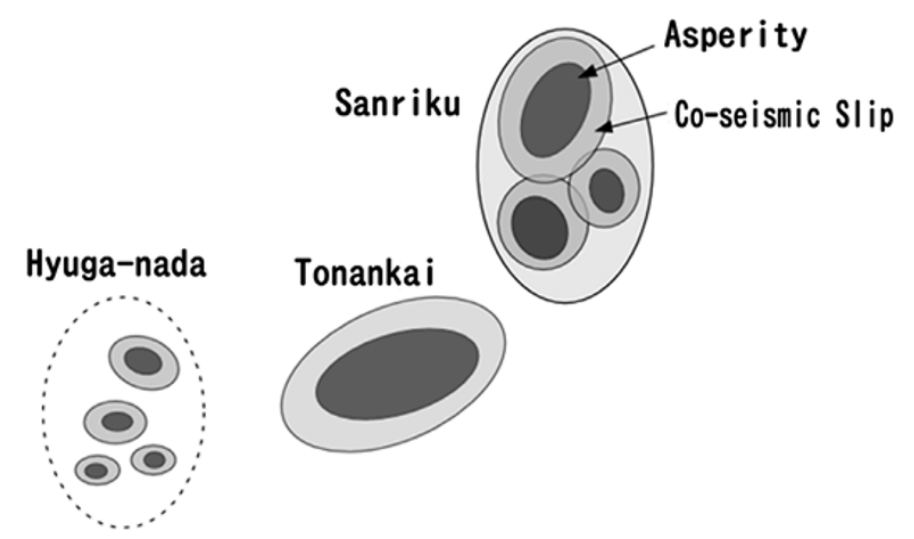

Fig. 9. Three distinct patterns of asperity distribution. (a) off-Sanriku type (b) Tonankai type (c) Hyuga-nada type.

\subsection{Sea bottom topography}

It is also interesting to compare the derived asperity with the sea bottom topography. Figure 10 shows the sea bottom topography around the Nankai trough, which was obtained by the Hydrographic and Oceanographic Department of the Japan Coast Guard. It can be clearly seen that the dislocation distribution (asperity) is well correlated with the topography. Although the specific mechanism for this has yet to be iden- tified, it is very likely that the repetition of the fault motions in the same area has built up the topography. In fact, Wells et al. (2002) summarized a good correlation between the asperities of megathrust earthquakes and the forearc basins. Such a correlation is very important for the identification of asperity for large earthquakes, especially in those areas where historical records, such as seismograms, are not available. 


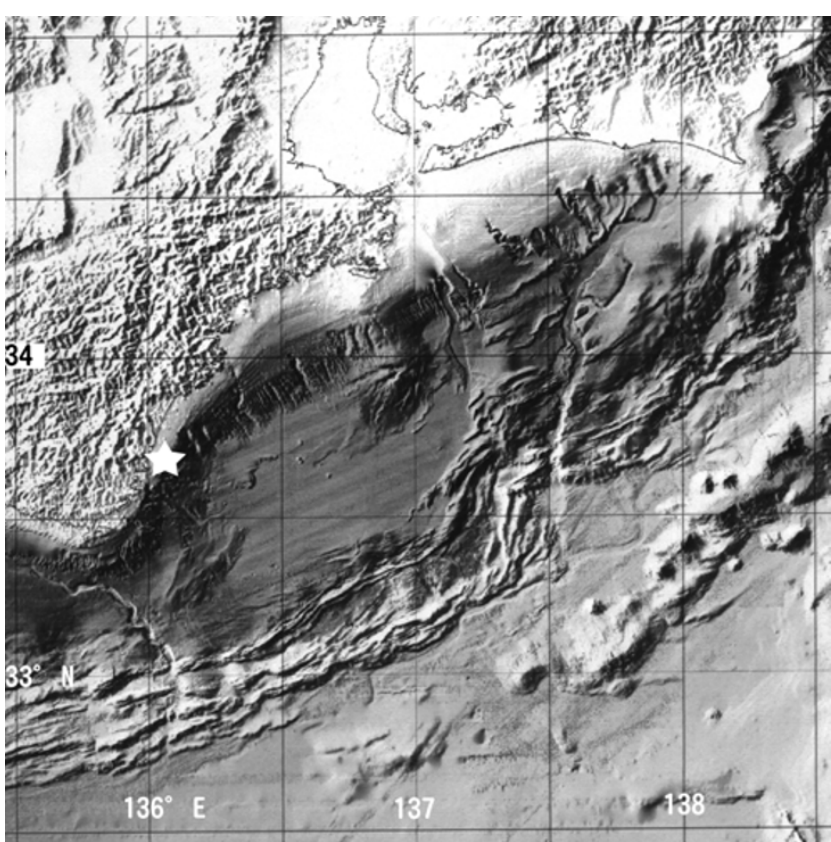

Fig. 10. Sea bottom topography obtained by the Japan Coast Guard. The basin structure off Kumano-nada seems to well correlate the asperity of the 1944 Tonankai earthquake.

\section{The Mikawa Earthquake of January 13, 1945}

A month after the Tonankai earthquake, the Mikawa earthquake occurred over a portion of the areas damaged by the Tonankai earthquake. This earthquake occurred at 03:38 am local time, at dawn, on January 13 (18:38 Jan. 12 UT), 1945. The JMA magnitude of this earthquake was 6.8 , which was not very large, but the earthquake devastated the region, causing the deaths of 2,306 persons, and 7,221 totally destroyed houses (Iida, 1978). The earthquake surface fault (e.g. the Fukouzu fault) appeared in the source area. The surface fault revealed a hook-shaped fault trace, consisting of mainly two segments, as shown in Figure 11 (Inoue, 1950; Hirono et al., 1951). Both segments are reverse faults with a vertical component of 1-2 $\mathrm{m}$ and a slight lateral component of $0.2-0.6 \mathrm{~m}$. The sense of the lateral component is such that the NS striking fault has a right lateral component, and the EW striking fault has a left lateral component. Several fault models have been proposed from geodetic data (Ando, 1974), seismicity (Hamada, 1987), and seismic records (Kakehi and Iwata, 1992) so far.

We tried to find as much low-gain seismograph data of the CMO as possible, and finally chose 13 wave traces recorded at five stations. Our first purpose is to clarify the size of the earthquake, and compare the value of Mw with JMA's magnitude M. Our second purpose is to determine the fault mechanism, and compare it with the observed surface rupture. We also have concerns with the relation of this earthquake to previous great earthquakes, including the 1944 Tonankai earthquake (M7.9) and the 1891 great Nobi earthquake (M8.0). In addition, we derive the asperity distribution, and compare it to the damaged area.

Table 3 shows the observation stations. The digitized and calibrated waveforms are shown in Fig. 12. It can be clearly seen that the record at GIF (Gifu) showed the largest

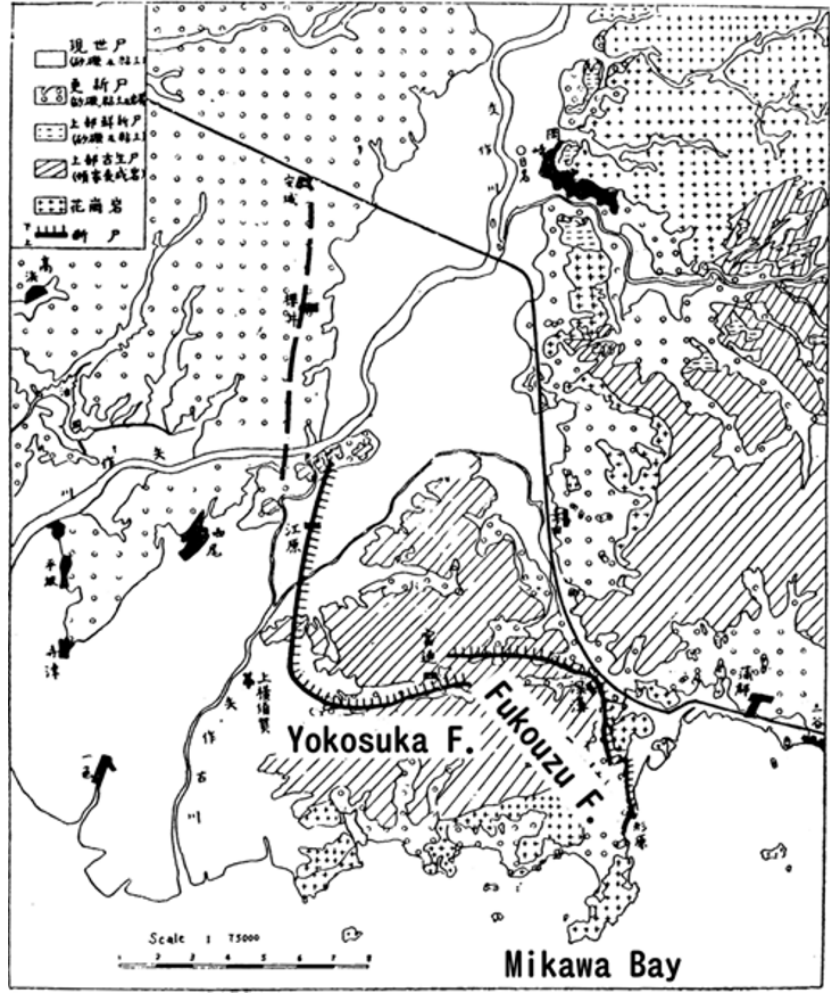

Fig. 11. Earthquake surface faults associated with the 1945 Mikawa earthquake (Inoue, 1950).

amplitude among all the records. This suggests that the rupture propagated in a northerly direction.

In the calculation of Green's functions, the same layered structure as the previous one was used, and the initial break was assumed at the epicenter obtained by Hamada (1987). The dip angle being fixed as $30^{\circ}$, we adopted the following three values for the fault strike found in the literature:

(1) $\mathrm{N} 180^{\circ} \mathrm{E}$ (Ando, 1974)

(2) $\mathrm{N} 135^{\circ} \mathrm{E}$ (Hamada, 1987)

(3) $\mathrm{N} 160^{\circ} \mathrm{E}$ (Kakehi and Iwata, 1992)

The grid scheme was constructed for each fault model and inversion was carried out with the following discretization parameters.

$$
\Delta x=\Delta y=5 \mathrm{~km}, \quad \tau=1 \mathrm{~s}, \quad N_{h}=5
$$

We found that the Hamada model gave the best-fit solution.

\subsection{Results and earthquake surface fault}

Figure 13 shows the final result. Table 4 shows the main source parameters. The fault mechanism is a reverse-fault with a pressure axis at the ENE-WSW direction. Although the surface fault reveals hook-shaped traces, the source fault seems to be well modeled by a single planar fault striking NW-SE. The sense of the lateral components both for the NS striking and EW striking faults is also in harmony with our fault mechanism if we consider a slight convergence from a planar fault at the deeper region to a concave or convex fault near the ground surface.

\subsection{Tectonic stress field}

The pressure axis of ENE-WSW is slightly rotated from the typical compression axis in western Japan. On the other hand, the tension axis of the Mikawa earthquake is nearly 


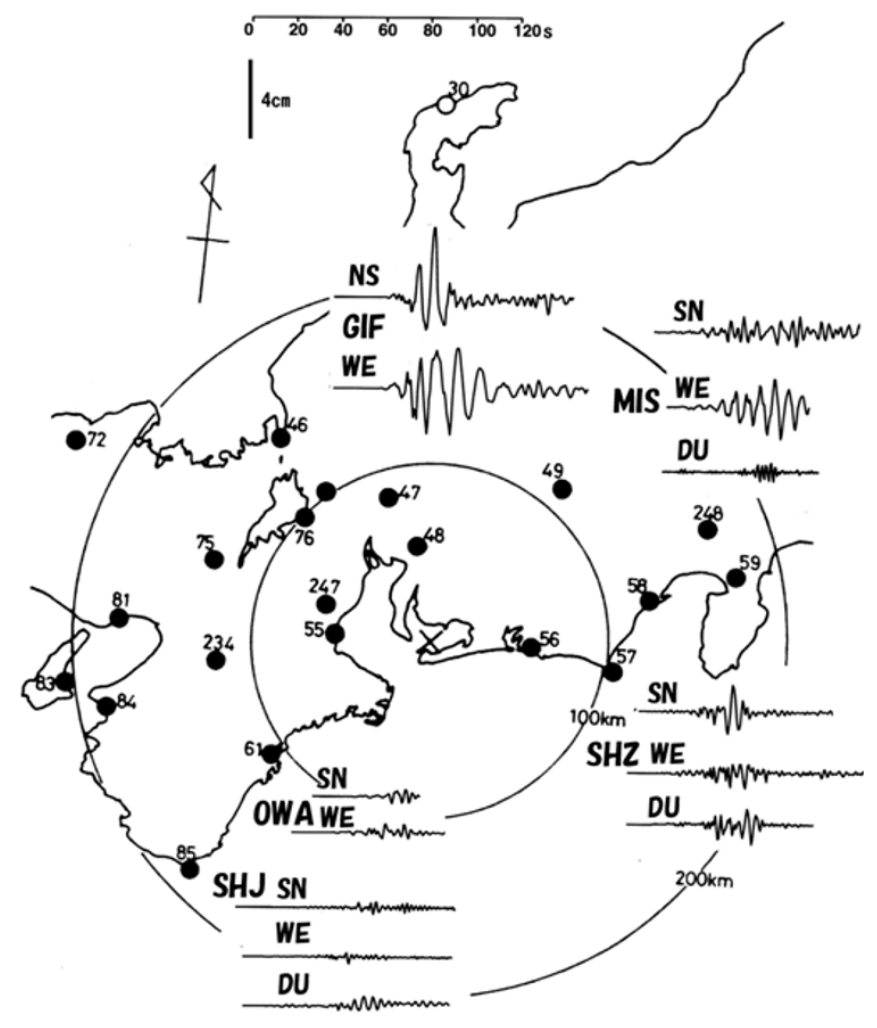

Fig. 12. Low-gain seismograph records of the 1945 Mikawa earthquake. The amplitude and the time axes are corrected to the common scale. Closed circles indicate the JMA stations. GIF:47; OWA:61; SHZ:58; MIS:59; SHJ:85.

Table 3. Source and station parameters for the 1945 Mikawa earthquake used in the present inversion.

(a) Source information

Origin Time: 1945/01/12 18:38 UT

Epicenter: Lat. $34.70^{\circ} \mathrm{N}$ Lon. $137.10^{\circ} \mathrm{E} \quad$ Depth $=10 \mathrm{~km}$

(b) Station parameters

\begin{tabular}{|c|c|c|c|c|c|c|c|c|}
\hline Station & Code & $\Delta[\mathrm{km}]$ & $\phi_{a}\left[^{\circ}\right]$ & $T_{p}[\mathrm{~s}]$ & $T_{S}[\mathrm{~s}]$ & & Comp. $\left(T_{0}[\mathrm{~s}], \mathrm{h}\right)$ & \\
\hline Gifu & GIF & 83.4 & 338.7 & 14.2 & 25.4 & NS $(5.0,0.2)$ & WE $(5.0,0.2)$ & \\
\hline Owase & OWA & 108.9 & 230.0 & 18.5 & 32.9 & SN $(3.1,0.3)$ & WE $(3.1,0.3)$ & \\
\hline Shizuoka & SHZ & 123.1 & 75.4 & 20.8 & 37.0 & SN $(4.0,0.2)$ & WE $(3.5,0.2)$ & DU $(3.0,0.3)$ \\
\hline Mishima & MIS & 173.0 & 74.1 & 29.0 & 51.0 & $\mathrm{SN}(4.5,0.2)$ & WE $(5.7,0.1)$ & DU $(2.0,0.1)$ \\
\hline Shionomisaki & SHJ & 185.9 & 221.9 & 30.9 & 54.3 & $\mathrm{SN}(2.3,0.1)$ & WE $(2.3,0.1)$ & DU $(3.2,0.2)$ \\
\hline
\end{tabular}

vertical, which is very different from the typical NS extension axis in western Japan. One possibility for this difference is that the 1944 Tonankai earthquake could have caused a change in the stress field. According to Yoshioka and Hashimoto (1989), however, it may have triggered the Mikawa earthquake but the stress change seems much smaller than the tectonic stress. Another interpretation is that the tectonic stress in the Mikawa region is different from the general tendency of the stress field in southwest Japan. In fact, the focal mechanism of the recent small earthquakes in this region is mainly a reverse fault with a NW-SE strike, almost similar to that of the Mikawa earthquake (Matsumura et al., 2002). Thus, it seems likely that the major fault motion itself manifested the stress field prevailing in the source re- gion, even though the 1944 Tonankai earthquake might trigger the Mikawa event. Iida and Sakabe (1972) pointed out that this fault may continue to the northwest and further to the Nobi earthquake fault, which was formed in 1981. The present mechanism seems to support their interpretation.

\subsection{Rupture propagation}

The rupture started at the deepest point at the southern end of the fault plane, and propagated toward the northwest direction. This pattern is consistent with the result obtained by Kakehi and Iwata (1992). There are two asperities: one near the hypocenter, and the other $10-15 \mathrm{~km}$ northwest from the hypocenter. The maximum fault slip is $2.1 \mathrm{~m}$ in the latter asperity. The seismic moment is Mo $=1.0 \times 10^{19} \mathrm{Nm}(\mathrm{Mw}$ $=6.6$ ), and the source duration is $11 \mathrm{~s}$. These values are 
(a)

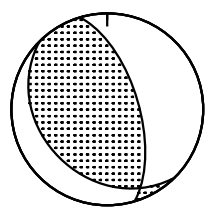

(135.,30., 65.) (b)

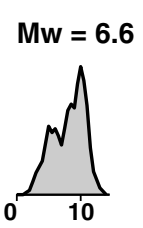

(c)

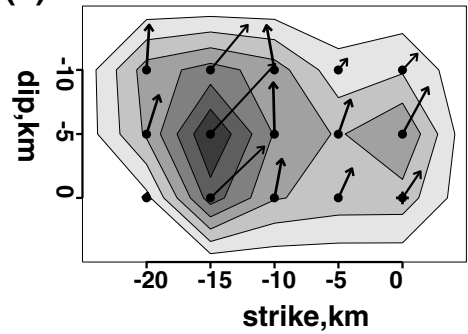

(d)

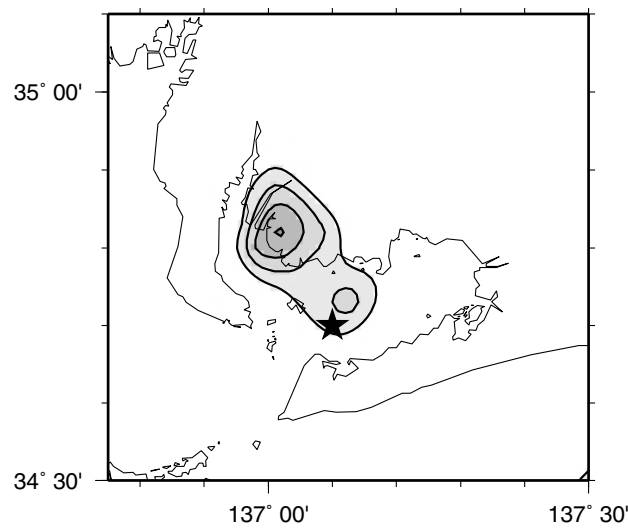

Fig. 13. Final solution of the 1945 Mikawa earthquake. (a) Mechanism solution; (b) Moment-rate function; (c) Slip distribution on the fault plane; (c) Map view of the slip. Star indicates the epicenter. Mainly two asperities are identified.

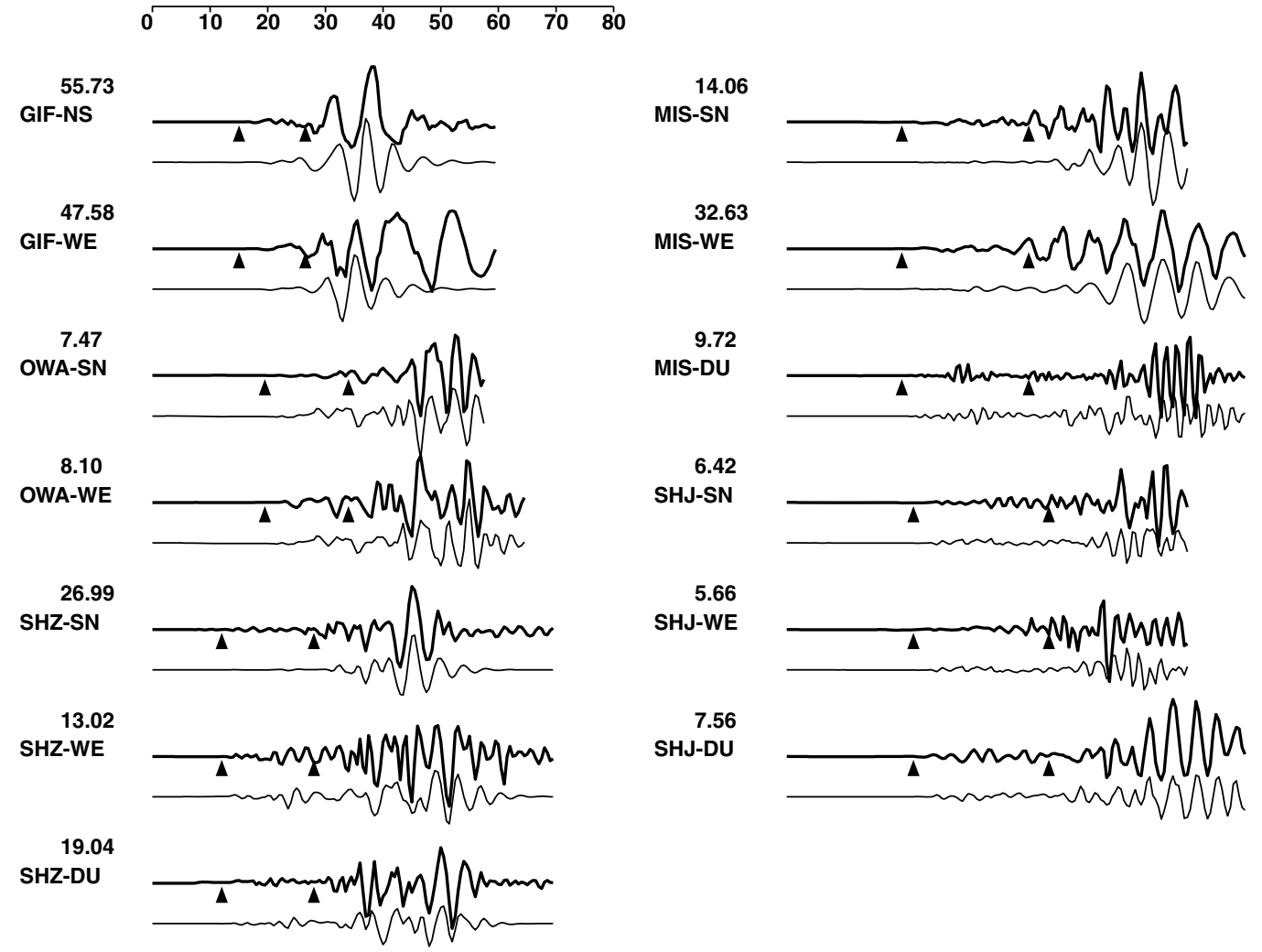

Fig. 14. Comparison of waveforms between the observed (upper trace) and the synthesized (lower trace) of the 1945 earthquake. For the notation, see the caption of Fig. 4(c). The travel times calculated for $P$ - and $S$-waves are given in Table 3(b). 


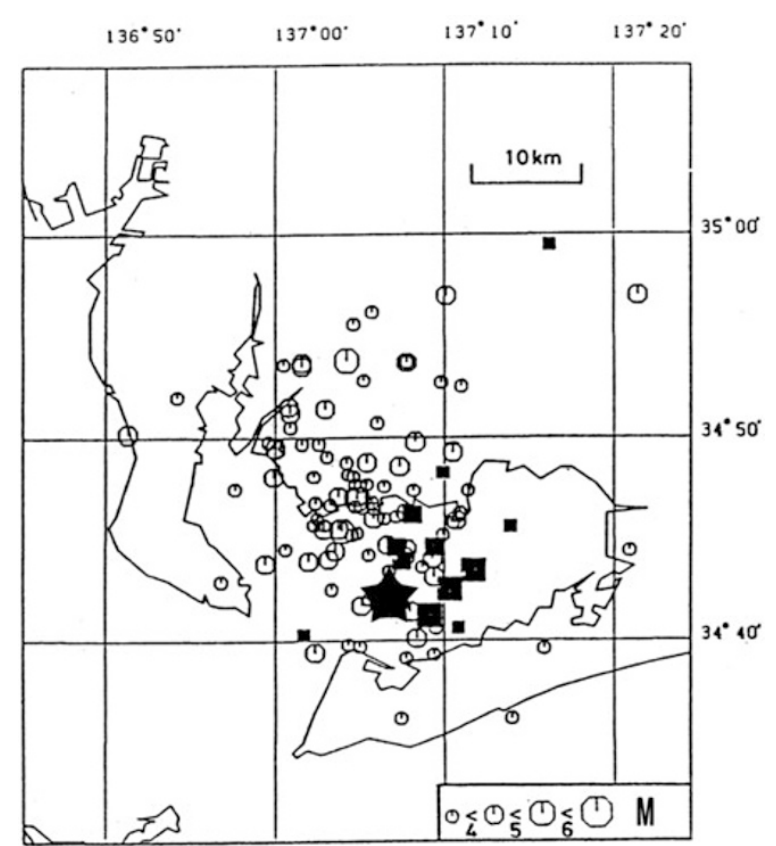

Fig. 15. Foreshocks and aftershocks of the 1945 Mikawa earthquake (Hamada, 1987). Star indicates the epicenter, and solid squares indicate foreshocks of the Mikawa earthquake or possible aftershocks of the 1944 Tonankai earthquake.

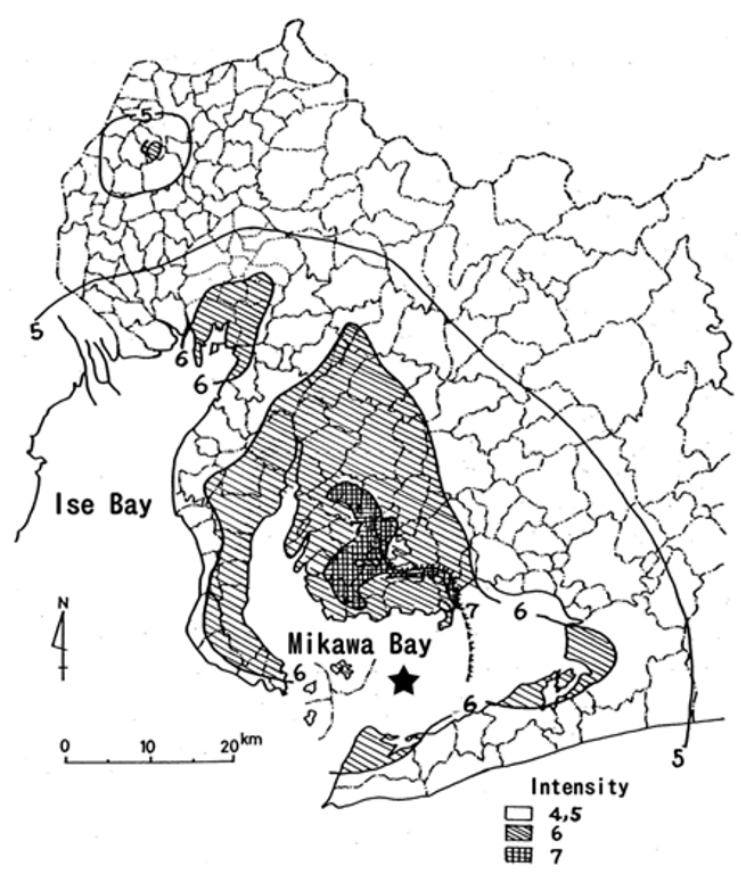

Fig. 16. JMA intensity distribution for the 1945 Mikawa earthquake (Aichi Prefecture Disaster Prevention Committee, 1978). Star indicates the epicenter.

Table 4. Comparison of the source parameters of the 1945 Mikawa earthquake.

\begin{tabular}{ll} 
(a) Present study & \\
\hline Fault mechanism & $($ Strike, Dip, Rake $)=\left(135^{\circ}, 30^{\circ}, 65^{\circ}\right)$ \\
Seismic moment & Mo $=1.0 \times 10^{19} \mathrm{Nm} \quad \mathrm{Mw}=6.6$ \\
Fault area & $S=20 \mathrm{~km} \times 15 \mathrm{~km}$ \\
Fault slip Maximum & $D_{m}=2.1 \mathrm{~m}$ \\
$\quad$ Average & $D_{a}=1.1 \mathrm{~m}$ \\
Stress drop & $\Delta \sigma=4.8 \mathrm{MPa}$ \\
Rupture front velocity & $V=2.5 \mathrm{~km} / \mathrm{s}$ \\
\hline
\end{tabular}

\begin{tabular}{|c|c|c|c|c|}
\hline Reference & Data & Mechanism & $\begin{array}{c}\text { Mo } \\
\times 10^{19} \mathrm{Nm}\end{array}$ & $\mathrm{Mw}$ \\
\hline Ando & Geodetic data & $\left(180^{\circ}, 30^{\circ}, 117^{\circ}\right)$ & 0.87 & 6.6 \\
\hline Hamada & Aftershocks, $P$-wave & $\left(135^{\circ}, 30^{\circ}, 60^{\circ}\right)$ & & \\
\hline Kakehi & Strong motion & $\left(160^{\circ}, 30^{\circ}, 98^{\circ}\right)$ & 1.0 & 6.6 \\
\hline This study & Strong motion & $\left(135^{\circ}, 30^{\circ}, 65^{\circ}\right)$ & 1.0 & 6.6 \\
\hline
\end{tabular}

in good agreement with the previous studies (Table 4(b)). The fault area of the major slip is roughly estimated from Fig. 13(c) as $S=20 \mathrm{~km} \times 15 \mathrm{~km}$. The averaged dislocation is calculated as $D_{a}=M o / \mu S=1.1 \mathrm{~m}$. The rupture front velocity is determined by the grid search method as $V=2.5 \mathrm{~km} / \mathrm{s}$. The stress drop is calculated from $M o$ and $S$ as $\Delta \sigma=2.5 \mathrm{Mo} / \mathrm{S}^{1.5}=4.8 \mathrm{MPa}$. These values are typical values of a shallow inland earthquake.

\subsection{Unsolved structure effect}

Figure 14 shows the comparison between the observed and the synthetic waveforms. Although the agreement of the waveforms is largely good, an unsolved misfit between the observed and synthetic waveforms still remains. Especially at GIF, the waveform with a period of about ten seconds is not well reproduced in the synthetic waveform. Kakehi and Iwata (1992) noticed this unusual long-period component at
GIF, and tried to explain it by assuming the pendulum period of as long as $10 \mathrm{sec}$, in spite of the face value of $5 \mathrm{sec}$. We checked this possibility by inspecting the free oscillation curves before and after the Mikawa event, and found that the pendulum period was almost unchanged around 5 sec. Therefore, it seems likely that the long period component may come from the surface waves related to the underground structure of a thick Nobi plain (Furumura, in written communication). We will examine these details in the future.

\subsection{Aftershocks and damage distribution}

Figure 15 shows the aftershock distribution relocated by Hamada (1987). The aftershocks seem to occur more frequently in the region surrounding the asperity. Figure 16 shows the distribution of seismic intensity reported by the Aichi Prefecture Disaster Prevention Committee (Iida, 1978). It can be perceived that JMA intensity 6-7 appears in 
the northern area of the epicenter. This heavily damaged area is well correlated with the northern asperity. Recently, Irie et al. (2002) reproduced the intensity distribution, taking into account the three dimensional underground structure and the asperity distribution based on our analysis.

\section{Summary}

We gathered low-gain strong motion records for two devastating earthquakes in western Japan: the 1944 Tonankai earthquake (M7.9), and the 1945 Mikawa earthquake (M6.8), and analyzed the records to derive the spatiotemporal distribution of the co-seismic fault motion.

The slip distribution obtained for the Tonankai earthquake shows that the source roughly consists of a single asperity with a length scale of $100 \mathrm{~km}$, without any smaller segment structure. This feature is very much in contrast to the other subduction zones in Japan, such as the off-Sanriku and Hyuga-nada regions. The main source parameters of the Tonankai earthquake are as follows: the seismic moment $=1.0$ $\times 10^{21} \mathrm{Nm}(\mathrm{Mw}=7.9)$; the fault area $=140 \mathrm{~km} \times 80 \mathrm{~km}$; (strike, dip, rake $)=\left(225^{\circ}, 15^{\circ}, 79^{\circ}\right)$; the maximum dislocation is $4.4 \mathrm{~m}$ at about $120 \mathrm{~km}$ northeast from the epicenter, near the Shima Peninsula, and the averaged dislocation is $3.0 \mathrm{~m}$.

The source fault of the Mikawa earthquake is modeled roughly by a single planar fault, in spite of the complex traces of the earthquake surface fault. The inversion results show that the mechanism is a reverse fault with a slight left-lateral component. The pressure axis directs ENE-WSW, which is a little rotated from a typical compression axis prevailing in western Japan. This fault can be regarded as the southern extension of the Nobi earthquake fault system as proposed by Iida and Sakabe (1972). The main source parameters are as follows: the seismic moment $=1.0 \times 10^{19} \mathrm{Nm}(\mathrm{Mw}=6.6)$; the fault area $=20 \mathrm{~km} \times 15 \mathrm{~km}$; (strike, dip, rake $)=\left(135^{\circ}\right.$, $\left.30^{\circ}, 65^{\circ}\right)$; and the maximum and averaged dislocations are $2.1 \mathrm{~m}$ and $1.1 \mathrm{~m}$, respectively. The slip distribution mainly consists of two asperities: the one near the hypocenter, and the other $10-15 \mathrm{~km}$ northwest from it. The northwestern asperity is well correlated with the heavily damaged area.

Acknowledgments. We would like to thank Drs. Carlos Mendosa and Tomotaka Iwata for many valuable comments. This research was partially supported by Tokio Marine Kagami Memorial Foundation.

\section{References}

Aida, I., A source model of the tsunami accompanying the Tonankai earthquake of 1944, Bull. Earthq. Res. Inst. Univ. Tokyo, 54, 329-341, 1979 (in Japanese with English abstract).

Akaike, H., Likelihood and the Bayes procedure, in Bayesian Statistics, edited by J. M. Bernardo, M. H. Dergroot, D. V. Lindley, and A. F. Smith, pp. 143-166, Univ. Press, Valencia, Spain, 1980.

Ando, M., Faulting in the Mikawa earthquake of 1945, Tectonophysics, 22, 173-186, 1974.

G. S. I., Crustal movements in the Tokai district, Rep. Coordin. Comm. Earthq. Pred., 68, 273-333, 2002 (in Japanese).

Hamada, N., Re-examination of seismicity associated with destructive inland earthquakes of Japan and its seismological significance, Papers Meteorol. Geophys., 38, 77-156, 1987 (in Japanese with English abstract).

Hamamatsu, O., Historical table of seismographs for routine observations in J. M. A. network, Zisin, 19, 286-305, 1966 (in Japanese).

Hirono, T., S. Honma, Y. Iwai, I. Noyori, and U. Sekiguchi, Report on the field survey of the Mikawa earthquake of January 13, 1945, Q. J. Seismol. $J M A$, 15(3-4), 12-25, 1951 (in Japanese).
Ichikawa, M. and E. Mochizuki, Travel time tables for local earthquakes in and near Japan, Papers Meteorol. Geophys., 22, 229-290, 1971 (in Japanese with English abstract).

Ichinose, G. A., H. K. Thio, P. G. Somerville, T. Sato, and T. Ishi, Rupture model for the 1944 Tonankai earthquake (Ms 8.1) from the inversion of teleseismic and regional seismograms, J. Geophys. Res., 2003 (submitted).

Iida, K., Distribution of the Earthquake damage and Seismic Intensity caused by the Mikawa earthquake of January 13, 1945, Report of the Earthquake Section of Disaster Prevention Committee of Aichi Prefecture, 96 pp, 1978 (in Japanese).

Iida, K. and K. Sakabe, The extension of the Fukozu fault associated with the Mikawa earthquake in 1945, Zisin, 24, 44-55, 1972 (in Japanese with English abstract).

Inouchi, N. and H. Sato, Vertical crustal deformation accompanied with the Tonankai earthquake of 1944, Bull. Geogr. Surv. Inst., 21, 10-18, 1975.

Inoue, U., On the Mikawa earthquake of January 13, 1945, Q. J. Seismol. $J M A$, 14, 49-55, 1950 (in Japanese).

Irie, K., S. Fukumoto, and K. Kamae, Estimation of strong ground motions during the 1945 Mikawa earthquake, J. Struct. Const. Eng., 2002 (in Japanese with English abstract) (submitted).

Kakehi, Y., and T. Iwata, Rupture process of the 1945 Mikawa earthquake as determined from strong motion records, J. Phys. Earth, 40, 635-655, 1992.

Kanamori, H., Tectonic implications of the 1944 Tonankai and the 1946 Nankaido earthquakes, Phys. Earth Planet. Inter., 5, 129-139, 1972.

Kanamori, H. and D. L. Anderson, Theoretical basis of some empirical relations in seismology, Bull. Seism. Soc. Am., 65, 1073-1095, 1975.

Kato, T. and M. Ando, Source mechanisms of the 1944 Tonankai and 1946 Nankaido earthquakes: Spatial heterogeneity of rise times, Geophys. Res. Lett., 24, 2055-2058, 1997.

Kikuchi, M., M. Nakamura, M. Yamada, M. Fushimi, Y. Tatsumi, and K. Yoshikawa, Source parameters of the 1948 Fukui earthquake inferred from low-gain strong-motion records, Zisin, 52, 121-128, 1999 (in Japanese with English abstract)

Koketsu, K., The extended reflectivity method for synthetic near-field seismograms, J. Phys. Earth, 33, 121-131, 1985.

Matsumura, S. and Observation and Research Group of Crustal Activities in the Kanto-Tokai District, Focal mechanism solutions in the Kanto-Tokai district over the past 20 years, Tech. Note NIED, 224, 84 pp., 2002.

Nagai, R., M. Kikuchi, and Y. Yamanaka, Comparative study on the source processes of recurrent large earthquakes in Sanriku-oki region: the 1968 Tokachi-oki earthquake and the 1994 Sanriku-oki earthquake, Zisin, 54, 267-280, 2001 (in Japanese with English abstract)

Satake, K., Depth distribution of coseismic slip along the Nankai trough, Japan, from joint inversion of geodetic and tsunami data, J. Geophys. Res., 98, 4553-4565, 1993.

Tanioka, Y. and K. Satake, Detailed coseismic slip distribution of the 1944 Tonankai earthquake estimated from tsunami waveform, Geophys. Res. Lett., 28, 1075-1078, 2001.

Utsu, T., Encyclopedia of Earthquakes, 568 pp., Asakura Press, 1987 (in Japanese).

Wells, R. E., R. J. Blakely, Y. Sugiyama, and D.W. Scholl, Coseismic slip in great subduction zone earthquake-its relationship to subduction erosion and subsidence of the forearc, J. Geophys. Res., 2002 (submitted).

Yabuki, T. and M. Matsu'ura, Geodetic data inversion using a Bayesian information criterion for spatial distribution of fault slip, Geophys. J. Int. 109, 363-375, 1992.

Yagi, Y. and M. Kikuchi, Partitioning between seismogenic and aseismic slip as highlighted from slow slip events in Hyuga-nada, Japan, Geophys. Res. Lett., 30, 1087, 2003.

Yagi, Y., M. Kikuchi, S. Yoshida, and T. Sagiya, Comparison of the coseismic rupture with the aftershock distribution in the Hyuga-nada earthquakes of 1996, Geophys. Res. Lett., 26, 3161-3164, 1999.

Yoshida, S., Waveform inversion methods for the earthquake source, J. Phys Earth, 43, 183-209, 1995.

Yoshii, T., Y. Sasaki, T. Tada, H. Okada, S. Asano, I. Muramatu, M Hashizume, and T. Moriya, The third Kurayoshi explosion and the crustal structure in the western part of Japan, J. Phys. Earth, 22, 109-121, 1974

Yoshioka, S. and M. Hashimoto, The stress field induced from the occurrence of the 1944 Tonankai and the 1946 Nankaido earthquakes, and their relation to impending earthquake, Phys. Earth Planet. Inter, 56, 349-370, 1989.

M. Kikuchi (e-mail: kikuchi@eri.u-tokyo.ac.jp), M. Nakamura, and K. Yoshikawa 